\title{
EHMTI-0148. Perivascular spaces and headache: a population-based imaging study (MRI HUNT)
}

\author{
AK Husøy ${ }^{1 *}$, LM Honningsvåg ${ }^{1}$, AK Håberg ${ }^{1}$, K Hagen $^{1}$, M Linde${ }^{1}$, M Gårseth², LJ Stovner ${ }^{1}$ \\ From 4th European Headache and Migraine Trust International Congress: EHMTIC 2014 \\ Copenhagen, Denmark. 18-21 September 2014
}

\section{Background}

In three former studies headache sufferers (in particular migraineurs) had more perivascular spaces (PVS) on MRI than headache-free.

\section{Aim}

To evaluate the association between headache and PVS in a relatively large and population-based imaging study with a blinded design.

\section{Method}

The study was part of a large longitudinal epidemiological study (Nord-Trøndelag Health Survey (HUNT)). The 1006 participants were 50-65 years at inclusion, had participated in all previous HUNT studies (1,2 and 3), and had been randomly selected to a population-based imaging study of the head (MRI-HUNT, 2007-2009). The number of dilated PVS in the basal ganglia (BG) and hemispheric white matter (HWM) was compared in headache sufferers (migraine with and without aura, non-migrainous headache) and headache-free. Both cross-sectional and longitudinal analyses were performed.

\section{Results}

The cross-sectional analysis showed that migraineurs without aura in HUNT 3 had fewer PVS than headachefree $(\mathrm{OR}=0.84,95 \% \mathrm{CI}=0.75-0.95, \mathrm{P}$-value $=0.003)$ in $\mathrm{BG}$. In the longitudinal analysis those with migraine in only HUNT 2 were found to have fewer PVS than headachefree $(\mathrm{OR}=0.98,95 \% \mathrm{CI}=0.96-1.00, \mathrm{P}$-value $=0.049)$ in HWM. There was no relation between PVS and any other headache types.

\section{Conclusion}

In contrast to the findings of previous studies the present study showed no increase in number of dilated PVS among headache sufferers. Fewer PVS in migraineurs without aura may be an incidental finding.

No conflict of interest.

\section{Authors' details}

${ }^{1}$ Neuroscience, Norwegian University of Science and Technology, Trondheim, Norway. ${ }^{2}$ Radiology, Levanger Hospital, Trondheim, Norway.

Published: 18 September 2014

doi:10.1186/1129-2377-15-S1-F12

Cite this article as: Husøy et al.: EHMTI-0148. Perivascular spaces and

headache: a population-based imaging study (MRI HUNT). The Journal of Headache and Pain 2014 15(Suppl 1):F12.
Submit your manuscript to a SpringerOpen ${ }^{\bullet}$ journal and benefit from:

- Convenient online submission

- Rigorous peer review

- Immediate publication on acceptance

- Open access: articles freely available online

- High visibility within the field

- Retaining the copyright to your article

\section{SpringerOpen ${ }^{\circ}$}

(c) 2014 Husøy et al; licensee Springer. This is an Open Access article distributed under the terms of the Creative Commons Attribution License (http://creativecommons.org/licenses/by/2.0), which permits unrestricted use, distribution, and reproduction in any medium, provided the original work is properly cited. 